\title{
COMUNIDADES TERAPÊUTICAS, DROGAS E PODER PUNITIVO: IMPLICAÇÕES ÉTICAS AO TRABALHO PROFISSIONAL NO CAMPO DA SAÚDE MENTAL*
}

\author{
Raquel Coelho Correa de Aranjo \\ Marco José de Oliveira Duarte
}

\section{Para uma introdução: a reatualização conservadora do debate das drogas}

Neste texto, partimos das alterações em curso na Política Nacional de Drogas (PNAD) em sua dimensão da saúde, destacando, particularmente, a ascensão das comunidades terapêuticas (CT), como dispositivos-chave de sustentação desta nova lógica da política de drogas, em uma direção política que emerge em oposição ao paradigma da atenção psicossocial, ${ }^{1}$ e, principalmente, contrária à Política para Atenção Integral a Usuários de Álcool e Outras Drogas do Ministério da Saúde (BRASIL, 2003).

Nosso objetivo é problematizar as mudanças ocorridas e as tendências dessa nova política no país e suas implicações éticas e políticas ao trabalho profissional no campo da política de saúde mental e drogas. Nossa contribuição explora a proliferação destas instituições e do novo modelo de política de drogas em saúde mental, em possível relação com as tendências do exercício do poder punitivo.

DOI - 10.29388/978-65-86678-15-4-0-f.159-182

1 Cabe apontar uma advertência quanto aos diferentes usos da expressão "atenção psicossocial", distinguindo, terminologicamente, entre "modo de atenção psicossocial", nomenclatura proposta por Costa-Rosa (2000), que expressa um paradigma, e "modelo de atenção psicossocial", que se refere a uma proposta de sistema de política pública. Sem dúvida, ambos são produto da experiência da Reforma Psiquiátrica brasileira, que se contrapôs à Psiquiatria tradicional e ao modelo asilar-manicomial. Já a "Rede de Atenção Psicossocial" (RAPS) é o conjunto de dispositivos que constituem a estrutura administrativa dos serviços de saúde mental no Brasil, expresso no Anexo V da Portaria de Consolidação no 3 do Ministério da Saúde (BRASIL, 2017b). 
As alterações mais recentes na política pública de saúde mental, com destaque para Portaria GM/MS No 3.588, de 21 de dezembro de 2017 (BRASIL, 2017a), aprofundaram um movimento que já vinha ocorrendo em anos anteriores, uma disputa na correlação de forças no campo da saúde mental, que produz um deslocamento na referida política, do paradigma da Atenção Psicossocial, que privilegia os Centros de Atenção Psicossocial (CAPS) como dispositivo organizador do cuidado em saúde mental, em direção a uma reatualização do modelo asilar e de isolamento dos usuários.

A supracitada Portaria instituiu uma "nova" Rede de Atenção Psicossocial (RAPS), que reinseriu antigos serviços de saúde mental, com ênfase em intervenções de saúde medicalizadoras, paramédicas e hospitalocêntricas, além de reafirmar um lugar para as CT na referida política pública. Tal modelo "renovado", que traz muitos elementos da psiquiatria tradicional, vem tomando espaço na medida em que se produz uma combinação de dispositivos, harmonizando manicômios e CT, sendo que estas últimas surgem como elemento novo na cena pública da saúde mental, embora sua presença no Brasil não seja recente.

Trata-se, portanto, de uma "nova" lógica de cuidado em saúde mental, que produz uma desfiguração de dispositivos próprios do modelo da Reforma Psiquiátrica brasileira. Se no modelo de atenção psicossocial, os CAPS são o centro de gravidade organizacional da rede, a atual lógica traz duas mudanças fatais: aproxima as CT da condição de protagonistas do cuidado em álcool e outras drogas e coloca os CAPSad (Álcool e outras Drogas), pela modalidade do CAPSad IV, ${ }^{2}$ como linhas auxiliares de suporte a uma rede com perfil absenteísta.

Neste sentido, nossa análise recai, inevitavelmente, em grande medida, sobre as chamadas CT, que proliferaram vertiginosamente nos últimos 25 anos $^{3}$ e que são a expressão de um paradigma contrário ao modo da atenção psicossocial. As CT brasileiras surgiram ainda na década 1960, inspiradas no modelo estadunidense da Synanon (DE LEON, 2008; FRACASSO, 2017; AGUIAR,

2 O CAPSad IV atende pessoas com quadros graves e intenso de sofrimento decorrentes do uso de crack, álcool e outras drogas, previsto para funcionar $24 \mathrm{~h}$, com equipes multiprofissionais e que serão localizados em regiões metropolitanas, acima de 500 mil habitantes, junto a cenas de uso, com possibilidade de possuir até 20 leitos (BRASIL, 2017a).

3 Segundo Brandão e Carvalho (2017) quase $80 \%$ do total de Comunidades Terapêuticas (CT) no Brasil surgiram nos últimos 25 anos. O levantamento dos autores mostra que entre os anos de 1966 a 1995 existiam em torno de 408 CT no Brasil, entre 1996 a 2015 foram criadas 1542 CT, concentradas em sua maior parte na região sudeste do país. 
2014; DAMAS, 2013) e se mantiveram e proliferaram à margem do financiamento público. Entretanto, na década de 1990, fundaram a Federação de Comunidades Terapêuticas (FEBRACT) e a Confederação Nacional de Comunidades Terapêuticas (CONFENACT), que passam a buscar no Estado o reconhecimento da sua experiência como modelo de tratamento público para usuários de drogas. ${ }^{4}$

Desta forma, a FEBRACT e a CONFENACT buscaram maior reconhecimento e legitimidade, sistematizando um modelo e método comuns, como passaram a utilizar-se da produção bibliográfica de George De Leon (2008), psiquiatra radicado nos Estados Unidos, que passou a ser o paradigma de modelo, teoria e método a ser perseguido por essas entidades.

Nosso objetivo é propor uma reflexão para além da hipótese de uma reatualização da indústria da loucura, que disputa parcela do fundo público para privilegiar um nicho de mercado que explora a internação como fonte de obtenção de lucros. Propomos uma reflexão a partir de conexões, correspondências ou funcionalidades entre a saúde mental e o poder punitivo.

As inúmeras denúncias de violações de direitos humanos nas CT apontam a existência de práticas de tortura, exploração do trabalho dos usuários e de encarceramento privado, técnicas de disciplinamento restritiva de liberdade quanto ao acesso aos meios de comunicação, documentação, escolhas individuais de vestimenta, e remetem a situações semelhantes à prisionalização (CFP, 2018; IPEA, 2017).

A relação entre os campos saúde mental e jurídico-penal não é uma novidade, tendo em vista que a relação entre a psiquiatria e a criminologia no Brasil está estabelecida desde a segunda metade do século XIX. Ambas, apesar de sua especificidade, sempre atuaram como dispositivos importantes no exercício do controle social de parcela da sociedade tida como indesejável e/ou perigosa (RAUTER, 2003).

A novidade desta aproximação entre a loucura e o poder punitivo está em dois pontos: a utilização das drogas como fator estigmatizante para a conformação de um novo grupo social de indesejáveis aptos a serem aprisionados, seja pela criminalização da venda ou pelo consumo das drogas ilícitas; e a emer-

4 É o que observa, por exemplo, a pesquisadora Ana Regina Machado, em sua dissertação de mestrado, "Uso prejudicial e dependência de álcool e outras drogas na agenda da saúde pública: um estudo sobre o processo de constituição da política pública de saúde do Brasil para usuários de álcool e outras drogas”, de 2006, quando a autora entrevistou vários atores da política pública de drogas, ficando demonstrado que, na década de 1990, já se registrava um aumento na presença das Comunidades Terapêuticas reivindicando normatização de suas entidades. (MACHADO, 2006). 
gência, ou reatualização, do papel da religião como legitimador do exercício deste controle social, tal como ocorreu na Idade Média.

A partir de estudos precedentes na análise das CT pretende-se desvelar em que medida essas instituições podem guardar uma funcionalidade para as tendências do exercício do Poder Punitivo na América Latina na contemporaneidade.

\section{Comunidades terapêuticas: o modelo assistencial}

A CT, que constitui objeto de estudo nesta pesquisa, é tributária do modelo estadunidense, da Synanon, fundada em agosto de 1959, na cidade de Santa Mônica, no estado da Califórnia (DE LEON, 2008). Entendemos tratarse de mais do que a primeira dos Estados Unidos, mas da experiência que inaugura um modelo paradigmático de instituição que ganhará as características e delimitações que possuem hoje essa categoria de estabelecimento que proliferou em várias partes do mundo, incluindo a América Latina e o Brasil.

O livro de George De Leon (2008) constitui-se no discurso que organiza, no Brasil, tanto a disputa pelo poder entre as comunidades terapêuticas quanto a disputa das comunidades terapêuticas pelo poder político, institucional e econômico. ${ }^{5}$

Por isto, do livro "Comunidade Terapêutica: teoria, modelo e método" (DE LEON, 2008), extraímos, da didática utilizada pelo autor, o que constituise como mais útil para proceder a uma descrição daquilo que as CT adotam como discursos de si mesmas, seu ideal de existência e que servem de elemento distintivo entre "ser" e "não-ser" uma CT, com suas pretensas práticas consoli-

${ }^{5} \mathrm{Na}$ própria apresentação do livro pode-se verificar os indícios desse processo, quando o presidente da principal e mais influente Federação de Comunidades Terapêuticas do Brasil faz agradecimentos ao Dr. De Leon e ao psiquiatra Ronaldo Laranjeira, um dos maiores expoentes da psiquiatria tradicional no tema das drogas. Como se segue: "A publicação do livro Comunidade Terapêutica - Teoria, Modelo e Método, as palestras e o curso realizados pelo Dr. George de Leon no XX Congresso Brasileiro da ABEAD deram um impulso de grande significado para o trabalho desenvolvido pelas comunidades terapêuticas entre nós. A FEBRACT sente-se realizada por ter sido a responsável pela tradução do livro e pela presença do Dr. De Leon entre nós. O espírito democrático e a postura científica do Dr. Ronaldo Laranjeira, Presidente da ABEAD, permitiram que, pela primeira vez, a teoria, o modelo e o método da Comunidade Terapêutica fossem apresentados à Comunidade Científica Brasileira, dando início a um diálogo que deverá ser proveitoso para todas as partes". (DE LEON, 2008). 
dadas e legítimas. Assim, o autor se ocupa de abordar, em partes e capítulos distintos, as CT como: (a) conceito; (b) abordagem; (c) modelo; e (d) método.

$\mathrm{O}$ autor busca apontar que as CT são, fundamentalmente, uma abordagem de autoajuda, desenvolvidas fora de práticas médicas, psicológicas e psiquiátricas tradicionais e que surgiram para atender ao problema do abuso de drogas, com base no "tratamento da pessoa inteira", utilizando-se da comunidade de companheiros, em ambientes livres de drogas.

O método das CT teria sido desenvolvido a partir de experiências de tentativa e erro, entre os fundadores das primeiras instituições, que também eram participantes e administradores destas comunidades de autoajuda. Em 1976, o primeiro encontro nacional de trabalhadores de CT nos EUA construiu a primeira sistematização sobre o propósito, natureza e pauta das CT e De Leon (2008) resumiu as propostas apresentadas com o objetivo didático de definir os parâmetros destas diversas experiências.

A CT proporciona limites e expectativas morais e éticas de desenvolvimento pessoal; emprega o banimento potencial, o reforço positivo, a vergonha, a punição, o sentimento de culpa, o exemplo e o modelo de comportamento para fazer que ocorram a mudança e o desenvolvimento pessoais. [...] [constitui-se como] estrutura igualitária ou hierárquica, residencial ou não-residencial, com ou sem diferenciação de status, tamanho, tipos de membros, sistema aberto ou fechado, mobilidade vertical (DE LEON, 2008, p. 30-1).

Está previsto no método das CT o uso de medidas disciplinares para que o usuário de drogas, agora na condição de residente, possa facilitar a mudança de seus comportamentos negativos. Com o objetivo de provocar mudanças no indivíduo, procuram manter suas instalações com uma "separação social e psicológica" entre os residentes e o restante da sociedade. É desejável, por isso, que a CT mantenha suas instalações em ambientes rurais, longe dos centros urbanos, em espaços "livre de drogas", protegidos das influências do mundo externo, pois seriam más influências.

Em geral, independentemente do nível que as CT recebem de apoio público, o modelo de tratamento deve envolver ao máximo o esforço do residente no custeio da CT. Com isto, os residentes podem ser envolvidos na captação de recursos, por meio da distribuição de tarefas, compondo "equipes para campanhas de levantamento de fundos nas ruas, para buscar e levar bens doados, para administrar a despensa, para negociar por telefone com possíveis doadores etc." (DE LEON, 2008, p.114). Mesmo considerando que, em geral, a 
população assistida pelas CT é composta por indigentes, o autor sugere que, caso recebam alguma forma de benefício público ou auxílio para a alimentação, devem doar esses bens ao programa.

O programa controla todo o dinheiro dos residentes na CT. Residentes indigentes têm doação de seus cheques da assistência previdenciária para o programa como pagamento pela residência e o tratamento na CT, enquanto outros podem pagar taxas pessoais diretamente ao programa. Mas, independentemente do status fiscal, não se permite que os residentes tenham acesso ao seu próprio dinheiro durante sua estada na CT sem autorização especial (DE LEON, 2008, p. 236).

A organização da estrutura física das CT reflete a proposta de adoção de uma estrutura hierárquica de organização. A hierarquia também está presente na distribuição de trabalho interno dos residentes na rotina da instituição, com um entendimento de que o trabalho é elemento essencial do tratamento e que sua função está na facilitação da troca entre os residentes, produzindo "sentidos nos comportamentos, atitudes e valores de cada indivíduo que trabalha" (DE LEON, 2008, p. 146).

Essa divisão hierarquizada de trabalho pressupõe que entre os internos é dividida toda a responsabilidade de manutenção do espaço e da vida cotidiana, como toda uma cadeia hierárquica de supervisão que coloca os próprios residentes como agentes avaliadores e disciplinares de seus pares, em um constante sistema de vigilância.

A previsão de um sistema de privilégios e sanções disciplinares é um elemento característico do método das CT. Trata-se de "um sistema integrado de administração clínica e comunitária por meio do treinamento comportamental" (DE LEON, 2008, p. 231).

Os privilégios são descritos como recompensas concedidas pelo corpo de funcionários da CT aos residentes, como reconhecimento das mudanças de comportamento individual. Configura um símbolo concreto, concedido ao residente, que altera a visão da comunidade sobre o seu status na fase do tratamento, marcando uma hierarquia entre os residentes.

Os privilégios podem ser concedidos alterando a função ou a posição do trabalho exercido pelo residente, a concessão de licenças para saídas, folgas 
e tempo livre, pequenas quantias, mudanças de acomodações, posse de objetos pessoais, entre outras medidas. ${ }^{6}$

Inversamente, as sanções são medidas disciplinares aplicadas pelo corpo de funcionários, em desaprovação a comportamentos e ações interpretadas como violadoras das regras da instituição.?

As sanções cumprem a função de exercício da aprendizagem em vida comunitária e a manutenção da ordem social da CT. Objetiva-se o envolvimento de todos os membros para participarem da instituição na vigilância de comportamentos negativos. As sanções disciplinares são parte constitutiva do tratamento na CT e são consideradas intervenções clínicas e parte importante do processo de socialização do residente, através da "experiência de aprendizagem por consequências" (DE LEON, 2008, p. 243).

Dentro dos instrumentos disciplinares, o corpo de funcionários, com o intuito de facilitar ações disciplinares regulares, pode instruir o residente a sentar-se em um banco especial, a ficar em uma cabina de relacionamento ou a participar de encontros especiais. O referido banco é uma cadeira disposta em uma área de espaço comum, em que o residente infrator pode sentar-se indefinidamente até decidir se mudará seus comportamentos e atitudes. ${ }^{8}$

As formas de organização da CT são dispostas para o alcance da cura, da aprendizagem e da mudança do indivíduo, como formas de alcançar o obje-

6 "Por exemplo, os usuários abusivos de substâncias com frequência não conseguem distinguir privilégio de direito e resistem às exigências sociais de conquistar as coisas por meio do esforço. O sistema de privilégios da CT ensina aos residentes que a participação produtiva numa comunidade se baseia em conquistar as coisas por meio do esforço, e não em direitos adquiridos” (DE LEON, 2008, p. 232).

7 "Nos primeiros anos, as reprimendas verbais eram chamadas "cortes de cabelo", sendo ocasionalmente seguidas pela raspagem do cabelo dos membros homens ou pelo uso de toucas de meia para as mulheres. Essas práticas eram em geral as últimas medidas antes da expulsão. Embora todas tenham desaparecido, o termo "corte de cabelo" para designar reprimendas ainda é usado em muitos programas [...] O residente pode ser chamado ao escritório para ser confrontado por funcionários e companheiros. Ele fica de pé, sem reagir, diante de um membro do corpo de funcionários e vários companheiros e, por cerca de cinco minutos, é repreendido verbalmente, às vezes em voz alta, por seu comportamento persistentemente negativo" (DE LEON, 2008, p. 241).

8 "A cabina de relacionamento é uma mesa com duas cadeiras colocadas numa área comum em que os residentes podem manter conversações a dois, face a face. Semelhantes ao banco, a cabina também é usada como instrumento em ações disciplinares. O residente que comete uma infração maior ou menor recebe a tarefa de sentar o dia inteiro na cabina, revendo os comportamentos e atitudes relativos às suas infrações com outros residentes" (DE LEON, 2008, p. 250 - grifos no original). 
tivo de tratar o transtorno individual, porém, mantendo o propósito mais amplo, de transformar os estilos de vida e identidades pessoais. As tarefas de trabalho, domésticas e procedimentos prescritos aos internos fazem parte da manutenção dos estabelecimentos, portanto, são vistas como parte do tratamento e do processo de cura, dentro da expectativa institucional de convívio social, estando os internos em constante avaliação.

\section{As comunidades terapêuticas brasileiras}

A primeira CT instalou-se no Brasil no estado de Goiás, em 1968, contudo, ao longo dos anos de 1970 proliferaram em território nacional, sendo registrado o maior aumento na década de 1990. A expansão das CT pode ser explicada pelo aumento na demanda por tratamento a pessoas com abuso de drogas, sem haver nenhuma resposta do Poder Público para atendimento a esta demanda (MACHADO, 2006).

Enquanto não havia oferta de tratamento de saúde pública universal e diversa da internação psiquiátrica, as CT não somente se expandiram como opção de acolhimento da demanda por ajuda para lidar com o abuso de drogas, como, ainda, orbitaram o Estado reivindicando espaço na elaboração das políticas sobre drogas, localizadas quase que exclusivamente nos aparatos repressivos.

Outro aspecto importante deve-se ao fato de que a lógica absenteísta das CT não era contraditória com a política proibicionista em curso no Brasil. A legitimidade da maior parte das CT, por outro lado, se viu sustentada para além de si próprias, apoiadas nas suas vinculações com instituições religiosas, que lhe conferiam, ainda, suporte financeiro e logístico. As CT figuraram como instituições filantrópicas, o que, na história brasileira se constituiu como uma constante, na ausência de políticas públicas.

O primeiro documento estatal de reconhecimento político no Brasil sobre as CT foi a Resolução RDC - n 101, de 30 de maio de 2001 (BRASIL, 2001) da Agência Nacional de Vigilância Sanitária (ANVISA). Esta Resolução foi desenvolvida por um grupo de trabalho da ANVISA ${ }^{9}$ que estabeleceu uma

9 Participaram deste grupo de assessoria as seguintes áreas do Ministério da Saúde: Coordenação DST/AIDS da Secretaria de Políticas de Saúde, Assessoria de Saúde Mental da Secretaria de Assistência à Saúde, Unidade de Medicamentos Controlados da Gerência Geral de Medicamentos - ANVISA, Unidades de Infraestrutura Física e de Tecnologia da Organização de Serviços de Saúde da GGTES - ANVISA (BRASIL, 2001). 
série de critérios para o funcionamento destas instituições condizentes com estabelecimentos de saúde.

Em 2011, no entanto, o referido documento foi substituído pela Resolução RDC no 29, (BRASIL, 2011a, p.1), que além de alterar os critérios que estabeleciam os requisitos de segurança sanitária, suprimiu a nomenclatura CT para "instituições que prestem serviços de atenção a pessoas com transtornos decorrentes do uso, abuso ou dependência de substâncias psicoativas (SPA)". Assim, as CT foram classificadas como instituições em "regime de residência e que utilizam como principal instrumento terapêutico a convivência entre os pares".

De acordo com as explicações da Nota Técnica da ANVISA sobre tal Resolução (BRASIL, 2011b, p.3), entre as alterações, as CT passaram a ser enquadradas em "padrão condizente com as exigências cabíveis a 'estabelecimentos de interesse à saúde"'. Alteram-se os critérios de recursos humanos, substituindo a presença de profissional de nível superior da área da saúde ou Serviço Social, para qualquer profissional de nível superior. Retiram-se os critérios de número máximo de pessoas institucionalizadas, bem como o número máximo de ocupação de pessoas por quarto, retirando-se, assim, "a vinculação a normas que preveem exigências para estabelecimentos de saúde".

Cabe ressaltar que na Nota Técnica, uma das justificativas para elaboração da nova norma foi suscitada a partir da identificação, em 2010, pela Secretaria Nacional de Políticas sobre Drogas (SENAD) e pelo Ministério da Saúde, de que as CT que haviam sido selecionadas para obter financiamento público de leitos não possuíam cadastro das vigilâncias sanitárias dos seus respectivos estados, por não atingirem os critérios estabelecidos na norma anterior (BRASIL, 2011b, p.5).

As CT, ao obterem a sua regulamentação, foram enquadradas em um perfil de unidades de saúde e submetidas a uma série de normas que burocratizavam a regularização formal do que era o seu efetivo crescimento e o seu real funcionamento. Estas entidades continuavam a ocupar um vazio, ausente de CAPSad, frente a um clamor popular, impulsionado pela mídia, de que algo precisava ser feito perante os indesejáveis consumidores de drogas que transitavam pelas ruas.

Além disso, as CT já alcançavam razoável nível de organização na sociedade civil e frente ao Estado, agindo à revelia dos regulamentos que as pretendiam normatizar. Verifica-se uma ascensão à força destas organizações, com o poder de influir no Estado, para que este adeque os regulamentos e o interesse público de acordo com suas necessidades, e não o inverso. 
A partir de 2011, temos uma série de portarias e convênios que preveem o financiamento público das CT, ora pelo Ministério da Saúde, ora pelo Conselho Nacional de Políticas sobre Drogas (CONAD).${ }^{10}$ É possível observar, contudo, que até o início de 2016, a articulação política das CT em busca do fundo público encontrou mais êxito nos setores do governo federal que articulavam as políticas sobre drogas que não o Ministério da Saúde. Até aquele momento, as previstas pela Saúde esbarravam na falta de credenciamento das CT, não preenchendo os critérios do Ministério da Saúde.

Até o ano de 2015 observa-se uma escalada no acúmulo de forças das CT, porém, ao mesmo tempo, observam-se também resistências dentro da gestão pública a tais avanços. Contudo, a partir de 2016, com o impeachment da Presidente Dilma Rousseff e a assunção de um governo disposto a implementar um programa de governo diametralmente oposto ao que fora eleito, passou-se a observar o desmonte do modelo de atenção psicossocial, privilegiando um modelo absenteísta e condenando a redução de danos.

É nesse contexto que surge a Resolução no 01, de 09 de março de 2018 (BRASIL, 2018), que marca a mudança governamental sobre a Política Nacional de Drogas, que deve considerar "a posição majoritariamente contrária da população brasileira quanto às iniciativas de legalização de drogas" e a "promoção da abstinência" na reorganização da rede de cuidados, acolhimento e suporte sociais $\left(\right.$ Art. $\left.1^{\circ}\right)$. Se antes as CT significavam uma contradição com a política oficial de saúde mental, álcool e outras drogas, apesar da Portaria GM/MS 3.088/11 (BRASIL, 2011c) que as inseriram na RAPS, agora era o momento mais adequado para o fomento das instituições da Atenção Residencial de Caráter Transitório, as CT.

\section{O poder punitivo na América Latina neoliberal}

No Brasil, chega-se ao final da ditadura militar com 98 mil leitos em hospitais psiquiátricos (PITTA, 2011). Considerando o Censo demográfico bra-

${ }^{10}$ A esse respeito ver: Portaria GM/MS no 131, de 26 de janeiro de 2012 que instituiu "incentivo financeiro de custeio destinado aos Estados, Municípios e ao Distrito Federal para apoio ao custeio de Serviços de Atenção em Regime Residencial, incluídas as Comunidades Terapêuticas" (BRASIL, 2012); Lei 12.868/2013 que inclui as CT entre as entidades passíveis de receber isenção de contribuições para a seguridade social, a partir da Certificação de Entidade Beneficente de Assistência Social (CEBAS) (BRASIL, 2013) e a Resolução CONAD 01/2015 (BRASIL, 2015), "que viria a regulamentar o financiamento federal das CT em todo o território nacional" (IPEA, 2017). 
sileiro da época (BRASIL, 2004), a população brasileira era de aproximadamente 120 milhões, ou seja, a cada mil pessoas, uma estava sobrevivendo em um manicômio. Dados do Departamento Penitenciário Nacional (BRASIL, 2017c) informam que em 1990 havia cerca de 90 mil presos no Brasil. Ou seja, embora haja dificuldades com precisão de dados, os números da virada da década de 1980 para 1990 nos levam a crer que saímos da ditadura com mais pessoas privadas de liberdade por serem loucas ou usuárias de drogas do que por terem cometido crimes.

Trata-se de reconhecer a amplitude do poder punitivo, este que se traduz no exercício de um tipo de poder político de coerção estatal, consistente na capacidade do Estado de produzir as condutas puníveis (criminalização primária) e selecionar os indivíduos e grupos sociais criminalizados (criminalização secundária). Segundo Zaffaroni et al. (2003, p. 39) trata-se do "exercício do poder coativo do Estado em forma de pena". A tendência em associar os mecanismos de criminalização formadas pelo sistema penal do Estado, no exercício do direito penal e suas agências de coerção, não traduzem a amplitude do poder punitivo. Ocorre que a dimensão política do poder punitivo se caracteriza, principalmente, no exercício da vigilância, cuja potência de controle é muito superior a seleção penal individualizante impetrada na sociedade.

Desta forma, diversas outras agências que não pertencem ao sistema penal formal do Estado exercem uma parte considerável do poder punitivo, apesar de suas funções manifestas serem diversas do controle social punitivo. Zaffaroni et al. (2003) definem essas agências estatais como sistemas penais paralelos, ou seja, uma complexa rede de agências que possuem a função oculta de exercício do poder punitivo através do controle social punitivo. ${ }^{11}$

Por essa razão, utilizamos o aporte teórico-metodológico e as contribuições da criminologia crítica para buscar compreender como a institucionalização da loucura e do uso de drogas se articulam com o poder punitivo para promover um controle social de indesejáveis eficiente para a reprodução do capital.

O modelo punitivo do neoliberalismo produziu nos países do capitalismo central o encarceramento em massa, mas na América Latina temos uma consequência muito mais complexa e absurdamente violenta. Sendo nosso subcontinente uma grande instituição de sequestro, desde os tempos de colônia,

${ }^{11}$ Zaffaroni et al. (2003, p. 69) trazem como exemplo os médicos que exercem um poder de institucionalização manicomial aproximando-se das características da prisionalização, bem como as autoridades assistenciais na institucionalização de pobres urbanos. 
conforme assinalaram Zaffaroni e Batista (2006, apud ANITUA, 2015), a nossa história é marcada por um genocídio a conta-gotas, de eliminação física de grandes contingentes populacionais. Segundo Zaffaroni (2015b), em uma década somamos mais mortes por homicídios, na América Latina, do que as provocadas pelas bombas atômicas de Hiroshima e Nagasaki. Ocorre que estas mortes são normalizadas pela opinião pública latino-americana, tanto porque ocorrem aos poucos, quanto pelas características de suas vítimas, esmagadora maioria parte do exército de excluídos - no caso do Brasil, pretos, pobres, periféricos e favelados dos centros urbanos.

A desproteção institucional dos direitos sociais determina que a lei não é igual para todos. Da mesma forma que os direitos sociais são desmontados, as garantias de direitos individuais que deveriam operar no exercício do poder punitivo não são aplicáveis a todos os cidadãos do mesmo jeito, havendo uma desigualdade entre a dimensão normativa e a dimensão efetiva de tais direitos. Uma grave consequência destas transformações operadas na sociedade capitalista é a intensificação do que De Castro (2005) denomina de sistema penal subterrâneo.

A autora faz uma distinção entre sistema penal aparente e sistema penal subterrâneo. Enquanto aquele abarca o funcionamento oficial das agências, o outro se faz presente de forma não aparente, à margem da lei, das normas. $\mathrm{O}$ sistema penal aparente criminaliza condutas mais facilmente localizáveis, como a chamada "criminalidade" de rua e estabelece uma seleção estigmatizante, preferencialmente, sobre setores mais vulneráveis.

Embora proibidos pela legislação aparente, uma série de procedimentos diferenciados subsistem para as classes subalternas, como as violações de domicílio, violação do direito à própria imagem, prisões e detenções preventivas por prazos indeterminados, execução penal desumana, violação do acesso à informação, torturas, homicídios etc. Acobertam-se, assim, condutas ilegais de variadas formas, que vão desde uma valoração diferenciada, que relativiza o que realmente ocorreu até a negativa dos fatos (ZAFFARONI, 2015a; BATISTA et al., 2003; DE CASTRO, 2005).

Ainda que o Brasil e a América Latina possuam especificidades em relação aos países do capitalismo central, e neste sentido, devemos ser capazes de produzir um diagnóstico e teorias adequadas à nossa realidade, por outro lado, sofremos influências da lógica globalizada de política criminal. Isto posto, algumas obras contemporâneas da criminologia crítica, mesmo não sendo latinoamericanas, têm sido importantes para uma reflexão sobre o que seria, na 
América Latina, uma nova cultura de política criminal própria dos tempos neoliberais já mencionados.

Garland (2014) ao analisar um conjunto de regularidades nas radicais transformações na orientação das práticas penais ocorridas a partir dos anos 1970 na Grã-Bretanha e Estados Unidos, através da análise dos aspectos mais evidentes do referido período, funda um objeto de análise, mais amplo do que o que costumam utilizar os pesquisadores da questão criminal, denominado de "campo do controle do crime".

Nascimento (2014), ao apresentar a edição brasileira do livro de Garland (2014), adverte que é possível encontrar, especialmente nos EUA, o pioneirismo de uma série de práticas e realidades que invadiram o Brasil com cerca de 20 anos de atraso: o hiperencarceramento, protagonismo da questão criminal nos meios de comunicação, segmentação do espaço público com segregação de certos grupos e o elevado número de mortes, tanto decorrentes da prática criminosa quanto da repressão ao crime, com as estatísticas concentradas nos guetos pobres.

Dada a natureza dependente do capitalismo tardio latino-americano, as práticas dos países centrais são comumente importadas pelas elites latinas, produzindo um consenso baseado no argumento de autoridade científica, sendo reproduzidas tais práticas nas instituições dos sistemas penais domésticos. Todavia, os resultados dessas transposições são frequentemente imprevisíveis, seja pelas especificidades históricas, sociais, culturais e políticas latino-americanas, seja porque esses países não possuem estruturas de poder suficientes para controlar variáveis econômicas que podem ser determinantes para as políticas que se pretende importar, como controle de preços, índices de desemprego, estabilidade dos financiamentos etc. (NASCIMENTO, 2014).

Garland (2014) chama de previdenciarismo penal o modelo penal hegemônico até os anos 1970 (no Brasil, até o início dos anos 1990), cuja base filosófica de justificação estava assentada na perspectiva correcional da reabilitação e da reinserção do condenado. Embora presentes ainda hoje, os programas de reabilitação não mais reclamam a expressão máxima de ideologia do sistema ou de objetivo principal de qualquer medida penal. As sentenças condenatórias inspiradas em conceitos correcionais são abandonadas e substituídas pelos objetivos penais de retribuição, neutralização e gerenciamento de riscos.

No Brasil, um dos exemplos de incorporação estatal oficial desse abandono da tese correcionalista se situa na mensagem de veto da Presidência da República, dirigido ao Senado Federal, no processo que resultou na aprovação da Lei 9.714, de 25 de novembro de 1998, quando afirma que 
As penas privativas de liberdade, instituídas com a finalidade preponderante de promover a ressocialização da pessoa do delinqüente, estudada a sua aplicação prática ao lume de métodos científicos de política criminal, revelaram-se inadequadas e inábeis a propiciar a reintegração do detento ao convívio social [...] (BRASIL, 1998, p.37).

Para Garland (2014), quando ruiu a fé no ideal que constituiu o suporte estrutural do sistema, dissipou-se o arcabouço de crenças, valores e práticas sobre o qual a pena moderna foi erigida. O consenso sobre a inutilidade da reabilitação foi o primeiro indicativo do abandono do enquadramento moderno e constituição de uma nova cultura.

Se durante a maior parte do século $\mathrm{XX}$ as penas que se aparentavam meramente retributivas foram alvo de críticas, sem lugar no sistema penal moderno, nos últimos anos temos presenciado o ressurgimento da retribuição como um objetivo político generalizado. Proliferaram-se campanhas para agravar penas com legislações draconianas e de reivindicação de condições mais austeras de execução penal. A opinião publicável ultrapassou o tabu de inibição dos discursos vingativos e passou a privilegiar a punição que expressa o sentimento público de reprovação do ato criminalizado.

Durante a vigência do modelo penal-previdenciário, prevaleceu o discurso de confiança no progresso do combate ao crime e racionalização da justiça criminal. A erosão do modelo anterior também é marcada pela ascensão do medo do crime na cena pública, acentuando o tom emocional do discurso sobre crime e pena. $\mathrm{O}$ medo do crime ganhou relevância ao ponto de ser tratado como um problema em si, com políticas destinadas mais a proporcionar a "sensação de segurança" do que a prevenção ou repressão criminal propriamente dita. O crime é redramatizado e o estereótipo de criminoso deixa de ser o sujeito necessitado para constituir-se como um predador criminoso e violento, de incurável reincidência. Associada a essa imagem projetada, hegemoniza-se o discurso que invoca a revolta coletiva reivindicando menos impunidade, mais retribuição.

A nova cultura do controle do crime pós década de 1970 (GARLAND, 2014), que utiliza a vítima como peça de propaganda para campanhas da Lei e Ordem, transformou as vítimas em verdadeiros especialistas de política criminal, ao tratarem das necessidades de mudanças na legislação criminal. A vítima é transformada em herói, criando uma identificação do público com seu sofrimento, inclusive batizando leis em seus nomes. A retórica de que as vítimas de- 
vem ser protegidas, sua raiva exprimida e seus medos tratados, opõem agressor e vítima como se qualquer direito ou ganho ao agressor signifique perdas ou menos direitos para a vítima, projetada no imaginário como "poderia ter sido você" (GARLAND, 2014; ZAFFARONI, 2015a).

A proteção do cidadão como preocupação da política criminal não foi uma criação do neoliberalismo, tendo sido o critério de defesa social a fundamentação das políticas correcionalistas do século XX. Essa transformação refere-se à reação ao aumento dos índices criminais e ao crescente medo do crime (GARLAND, 2014), que passou a orientar as disputas políticas eleitorais.

O discurso criminal punitivista tornou-se o centro dos holofotes da disputa política, onde qualquer erro vira escândalo e a vantagem política na opinião pública é a meta. Portanto, o processo de formulação das políticas criminais "se tornou profundamente politizado e populista" (GARLAND, 2014, p. 57)

Assim, observou-se uma ênfase dada à necessidade de segurança, proteção do perigo e identificação e gerenciamento de riscos de todo tipo, de tal forma que tais questões passaram a justificar a oposição às garantias individuais comuns da prática processual penal.

O fenômeno do hiperencarceramento foi a principal e mais evidente marca deste período histórico neoliberal associado ao abandono do discurso crítico sobre a eficácia da prisão e o estabelecimento da opinião dominante de que "a prisão funciona" (GARLAND, 2014, p. 59). Tal discurso não reivindica mais o seu sucesso em função da reabilitação ou correção do condenado, "mas como instrumento de neutralização e de retribuição que satisfaz as exigências políticas populares por segurança pública e punições duras" (GARLAND, 2014, p. 59).

Assim, a prisão deixa a condição de "uma instituição correcional desacreditada e decadente para se tornar um maciço e aparentemente indispensável pilar da ordem social contemporânea" (GARLAND, 2014, p. 60).

No período pós 1970, um conjunto diferente passou a influir nas políticas governamentais, que passaram a ser informadas, basicamente, por teorias de controle. Nesta nova concepção do problema criminal, a delinquência é fruto da falta de controle adequado: controles sociais, situacionais, autocontroles. Enquanto as teorias anteriores admitiam uma perfeição do ser humano, entendendo o comportamento criminoso como socialização deficiente, as teorias do controle partem de uma visão mais obscura da humanidade: os indivíduos seriam fortemente propensos a assumir condutas egoístas, antissociais e criminosas, a menos que sejam inibidos de cometê-las. Para tanto, devem estar estabe- 
lecidos controles robustos e eficazes, sendo a edificação da autoridade da família, da comunidade e do Estado mecanismos de sustentar as restrições e assegurar o controle e a disciplina.

O novo enfoque se desloca para o gerenciamento do risco, uma lógica atuarial (DIETER, 2013), buscando atuar sobre as "situações criminogênicas" e diminuir as fontes de oportunidades para a ocorrência do evento criminoso. Como consequência, a nova orientação política é se concentrar na substituição da prevenção mediante cura pela redução das oportunidades, aumentando controles sociais e situacionais, modificando rotinas diárias, pouco importando o bem-estar dos grupos sociais necessitados (GARLAND, 2014, p. 62).

\section{Considerações finais ou novas problematizações para o debate}

$\mathrm{Na}$ nova cultura do controle do crime assim como se reinventam as prisões, são reinventados velhos mecanismos de isolamento dos usuários de drogas. A política de drogas na diferenciação da ação do Estado impõe tratamentos diversos entre o indivíduo identificado como traficante e o usuário identificado como doente. Contudo, a necessidade de controle social sobre esta parcela de indesejáveis estigmatizada pelo uso de algumas drogas nem sempre pode ser exercida pela prisão.

Em um contexto de demanda por neutralização de indesejáveis, a reinvenção da prisão atinge a todos aqueles percebidos como desviantes. A população de rua rotulada como usuária de crack demanda, entretanto, um tratamento diferenciado do tratamento penal comum. A necessidade de lançar mão de instrumentos de neutralização pela via da psiquiatria tampouco pode dar conta satisfatoriamente dessa população. A Reforma Psiquiátrica brasileira reduziu significativamente os leitos de internação psiquiátrica, ao passo que a população brasileira aumentou. As comunidades terapêuticas (CT), assim, emergem como a agência adequada a tratar essa parcela da população, situando-se entre a resposta médica e a punitiva, para sujeitos que são representados no imaginário social como potenciais criminosos, imprevisíveis, e que não respondem por si mesmos.

Enquanto uma das características mais marcantes da política criminal contemporânea é a erosão da perspectiva correcionalista, do ideal de reabilitação, as CT estão fundadas justamente neste ideal. Nada há hoje no Brasil de mais idealista quanto a um ideal de reabilitação do que as CT. Seu principal dis- 
curso de legitimação é a capacidade de recuperar dependentes químicos, portanto, sua denominação supõe um lugar de "terapia" e sua missão é a cura de indivíduos adoecidos. ${ }^{12}$

A primeira problematização a se fazer diante disso é que, tal como ocorria nas prisões, há uma distância abissal entre a promessa do discurso correcionalista e sua efetividade. Segundo Alarcon (2008), a literatura especializada apresenta como consenso que apenas entre 20 a 30\% dos pacientes conseguem a abstinência total. ${ }^{13}$

Não nos pode escapar, ainda, que embora seja previsto para os residentes um programa de reabilitação, o Relatório de Inspeção das CT de 2018 (CFP, 2018) aponta a ausência de projetos terapêuticos singulares em 18 dentre 28 estabelecimentos selecionados.

A segunda questão remete ao ângulo de análise que deve ser feito em relação ao declínio do ideal de reabilitação. Não se trata de sobrepor a CT e o declínio do ideal de reabilitação como critério de verificação de compatibilidade. Precisamos analisar se, na periferia do capitalismo, a superveniência de uma instituição que se vende como sucesso de reabilitação é útil na lógica de política criminal vigente. Como dispositivo de um sistema penal paralelo e complementar da política criminal oficial, podemos considerar algumas questões para explicar essa funcionalidade do discurso de reabilitação.

As CT se dirigem ao mesmo público que o sistema penal intenta controlar. Com as tendências mais recentes de retomada das internações psiquiátricas e a reafirmação de instrumentos de internação, a voluntariedade para a internação em CT pode aparecer de forma viciada. A CT é uma opção aparentemente voluntária, que pode evitar medida mais grave, como prisão ou internação psiquiátrica.

$\mathrm{Na}$ periferia do capitalismo, o correcionalismo e a retribuição não demonstraram nenhuma contradição, funcionando o discurso correcional como mera legitimação a encobrir práticas herdadas da escravidão, de açoites e castigos físicos. Da mesma forma, sem abrir mão do suplício e das mortes que marcam a realidade político-criminal latino-americana, o discurso correcionalista legitima a demanda por neutralização, que nem sempre pode ser alcançada pela

12 A perspectiva da reabilitação está estampada em muitos dos nomes adotados por várias CT: Associação de Reabilitação Paraíso da Vida, Centro de Recuperação e Reabilitação Vida Plena, Centro de Reabilitação Cidade Viva. (CFP, 2011).

${ }^{13}$ Ver também: "Tem-se que quase a metade dos 138.568 acolhidos em CTs, durante 2015, havia estado em instituições semelhantes anteriormente. De fato [...] a parcela dos internos reincidentes é superior à daqueles que irão completar o tratamento; e nada menos que 55\% o abandonam antes de concluí-lo" (NATALINO, 2018, p. 53). 
via do sistema penal, pois este nem sempre pode prescindir das garantias processuais penais.

No contexto neoliberal, faz mais sentido tentar conter indesejáveis por meios menos dispendiosos, como uma CT, do que por meios mais caros como a prisão. Em todo caso, o discurso correcionalista das CT funciona como uma miragem de redenção possível, um estelionato praticado em meio a já descrença total de que usuários de drogas possam ter qualquer reabilitação. Nem a ascensão, hoje, das CT, significa que o ideal de reabilitação não tenha ruído, nem esta erosão do ideal de reabilitação é incompatível em considerar as CT como instrumentos integrados à política criminal contemporânea.

O estigmatizado usuário de crack das ruas é visto como um sujeito periculoso e que não se enquadra na teoria da escolha racional, teoria própria da nova cultura do controle do crime. Apesar de cometer, em geral, pequenos crimes, este sujeito é representado ora como um perturbador do ambiente, ora como um sujeito imprevisível, capaz de uma atroz violência por motivos banais, precisando ser contido antes que produza danos. Assim, instituições que se situam no meio do caminho entre o tratamento moral e a punição propriamente dita, com objetivos meramente neutralizadores, fazem todo o sentido.

As campanhas midiáticas em torno da suposta "epidemia" do crack surgiram como ascensão do medo do crime e da "nova" droga na cena pública. Os meios de comunicação utilizaram-se de um acentuado tom emocional no discurso sobre as cenas de uso, ou cracolândias, construindo uma ideia de usuário do crack como sujeito incapaz de se determinar, sempre em busca de consumir mais droga e disposto ao cometimento de qualquer ação, incluindo furtos e roubos, para lograr êxito em conseguir mais drogas.

A opinião pública passou a clamar por uma ação contundente do Estado a este drama relatado nos noticiários dos jornais, que acentuou uma representação demonizada em relação às drogas e a repulsa aos drogados. A revolta coletiva sobre o problema do crack nos grandes centros urbanos do país ensejou a criação de uma política que deveria, no seu conteúdo, parecer mais enérgica, mais eficaz na resolução do problema. Ocorre que as agências policiais se viram incapazes de lidar com essa demanda, pois se tratava de um tipo especial de usuário, que se não fosse flagrado furtando, não permaneceria preso. A solução aparece com a entrada das CT na política pública, como instituição apta a produzir o isolamento destes indesejáveis e periculosos, por um razoável período de tempo, limpando o medo das cidades brasileiras.

A adoção de uma política de internação desses usuários de drogas, concentrados nas cracolândias da cidade, convergia com a política criminal de guer- 
ra às drogas adotada pelo Estado brasileiro. A solução pela internação como recurso primeiro na forma de lidar com esta parcela da população se torna muito mais harmônica do que as políticas de convivência comunitária de redução de danos, além da proteção jurídica da clientela das CT ser muito mais deficiente do que a clientela do sistema prisional.

As famílias dos usuários de drogas são convocadas a prestarem seus depoimentos de como seus familiares eram antes do uso de drogas. Explora-se a posição das famílias como vítimas, primeiro no contato com a droga e depois na sua relação com um viciado periculoso. Adeptos de políticas absenteístas proferem discursos sobre como a falta de instituições de tratamento para desintoxicação do uso de drogas mantém os familiares de pessoas doentes do vício como reféns. Paralelamente, as vítimas e familiares de vítimas de violência cometidas por pessoas identificadas como usuárias de drogas, principalmente, moradores de rua, são utilizadas como peça de propaganda para campanhas de maior rigor na legislação proibicionista. Instala-se um duplo movimento em relação às drogas, o isolamento para tratamento do viciado e o aumento ao rigor do combate ao tráfico.

Sem pretender, esgotar as análises sobre o tema, buscamos verificar o quanto as CT se combinam com o campo de controle do crime contemporâneo, considerando, especialmente, a realidade brasileira e latino-americana, onde a política criminal ganha contornos específicos e distintos da política criminal dos países do capitalismo central. A força das CT pode residir muito mais na sua funcionalidade para o sistema de controle social e exercício do poder punitivo do que pela sua pretensa posição como instituição de tratamento e de "interesse à saúde". Afinal, tratar a conflitividade social pela via punitiva frente à juventude negra e pobre é o caminho histórico das classes dominantes para assegurar a ordem social desigual herdada da escravidão.

\section{Referências}

AGUIAR, A. L. V. de. Usuários de crack, instituições e modos de subjetivação: estudo das práticas e da eficácia terapêutica em uma comunidade terapêutica religiosa (RN). 2014. Dissertação (Mestrado em Antropologia) - Programa de Pós-graduação em Antropologia Social. Universidade Federal do Rio Grande do Norte, Natal, 2014.

ALARCON, S. O diagrama das drogas: cartografia das drogas como dispositivo de poder na sociedade brasileira contemporânea. 2008. Tese (Doutorado 
em Ciências) - Escola Nacional de Saúde Pública Sergio Arouca, FIOCRUZ, Rio de Janeiro, 2008.

ANITUA, G. I. Histórias dos pensamentos criminológicos. Rio de Janeiro: Revan, 2015.

BATISTA, N; ZAFFARONI, E. R.; ALAGIA, A.; SLOKAR, A. Direito penal brasileiro: primeiro volume - teoria geral do direito penal. Rio de Janeiro: Editora Revan, 2003.

BRANDÃO, B.; CARVALHO, J. Programa de Braços Abertos e as políticas de drogas na sociedade de controle: um diálogo histórico-antropológico. Outros Tempos. Maranhão, v. 14, n. 24, p. 184-206, dez. 2017.

BRASIL. Presidência da República. Mensagem no 1.447, de 25 de novembro de 1998. [Veto parcial ao Projeto de Lei no 2.684, de 1996 [...] que "Altera dispositivos do Decreto-Lei no 2.848, de 7 de dezembro de 1940 - Código Penal']. Lei $\mathrm{n}^{\circ} 9.714$, de 25 de novembro de 1998. Altera dispositivos do Decreto-Lei $\mathrm{n}^{\circ}$ 2.848, de 7 de dezembro de 1940 - Código Penal. Diário Oficial da União. Brasília, DF, seção 1, 26 nov. 1998. Disponível em: < https://www2.camara.leg.br/legin/fed/lei/1998/lei-9714-25-novembro-1998-352670-veto-19131pl.html.> Acesso em: 03 mar.2020

. Instituto Brasileiro de Geografia e Estatística, IBGE. Tendência demográficas: uma análise dos resultados da amostra do Censo Demográfico 2000. Rio de Janeiro: IBGE - Estudos e pesquisas, Informação Demográfica e Socioeconômica, n. 13, 2004.

Ministério da Saúde. Agência Nacional de Vigilância Sanitária. Resolução - RDC no 101, de 30 de maio de 2001. Diário Oficial da União. Brasília, 30 maio 2001.

- Ministério da Saúde. Secretaria de Atenção à Saúde. A política do Ministério da Saúde para atenção integral a usuários de álcool e outras drogas. Brasília, 2003.

. Ministério da Saúde. Agência Nacional de Vigilância Sanitária. Resolução - RDC nº 29, de 30 de junho de 2011. Diário Oficial da União, Brasília, 30 jun. 2011a.

- Ministério da Saúde. Agência Nacional de Vigilância Sanitária. Nota Técnica n. 01/2011 - [...] RDC n 29, de 30 de junho de 2011. Brasília, 30 jun. 2011b. 
. Ministério da Saúde. Portaria GM/MS No 3.088, de 23 de dezembro

de 2011. Institui a Rede de Atenção Psicossocial para pessoas com sofrimento ou transtorno mental e com necessidades decorrentes do uso de crack, álcool e outras drogas, no âmbito do Sistema Único de Saúde (SUS). Diário Oficial da União. Brasília, DF, 26 dez.2011, p. 230-232, n. 247, seção 1, 2011c.

. Ministério da Saúde. Portaria GM/MS no 131, de 26 de janeiro de 2012. Diário Oficial da União. Brasília, DF, 27 jan. 2012, seção 1, p. 40-41, 2012.

. Lei Federal no 12.868, 15 de outubro de 2013. Diário Oficial da União. Brasília, DF, 16 out.2013, seção 1, p. 1-2, 2013.

. Presidência da República Gabinete de Segurança Institucional. Conselho Nacional de Políticas sobre Drogas. Resolução No 01, de 19 de agosto de 2015. Diário Oficial da União. Brasília, DF, n. 165, 28 ago.2015, seção 1, p. 51, 2015.

. Ministério da Saúde. Portaria GM/MS No 3.588, de 21 de dezembro de 2017. Diário Oficial da União. Brasília, DF, n. 245, 22 dez. 2017, seção 1, p. 236-238, 2017a.

. Ministério da Saúde. Portaria de Consolidação nº 3 , de 28 de setembro de 2017. Diário Oficial da União. Brasília, DF, n. 190, 03 out.2017, supl., p. 192-288, 2017b.

. Ministério da Justiça e Segurança Pública. Departamento Penitenciário Nacional. SANTOS, T. (Org), ROSA, M. I. da (Colab.). Levantamento Nacional de Informações Penitenciárias - INFOPEN - Atualização jun. 2016, Brasília, DF, 2017c.

. Conselho Nacional de Políticas sobre Drogas (CONAD). Resolução $\mathrm{n}^{\circ}$ 01, de 09 de março de 2018. Diário Oficial da União. Brasília, DF, n.49, 13 mar. 2018, seção 1, p.128, 2018.

. Mecanismo Nacional de Prevenção e Combate à Tortura (MNPCT); Procuradoria Federal dos Direitos do Cidadão (PFDC) do Ministério Público Federal (MPF). Relatório da Inspeção Nacional em Comunidades Terapêuticas - 2017. Brasília, DF: Conselho Federal de Psicologia, 2018.

CONSELHO FEDERAL DE PSICOLOGIA (CFP). Relatório da $\mathbf{4}^{\mathbf{a}}$. inspeção nacional de direitos humanos: locais de internação para usuários de drogas. Brasília, DF, Conselho Federal de Psicologia, 2011. 
COSTA-ROSA, A. O modo psicossocial: um paradigma das práticas substitutivas ao modo asilar. In: AMARANTE, P. (Org.). Ensaios: subjetividade, saúde mental, sociedade. Rio de Janeiro: Editora FIOCRUZ, 2000.

DAMAS, F. B. Comunidades Terapêuticas no Brasil: Expansão, institucionalização e relevância social. Rev. Saúde Públ. Santa Cat. Florianópolis, v. 6, n. 1, p. 50-65, jan. / mar. 2013.

DE CASTRO, L. A. Criminologia da libertação. Rio de Janeiro, Revan: ICC, 2005.

DE LEON, G. A Comunidade Terapêutica: teoria, modelo e método. 2. ed. São Paulo: Loyola, 2008.

DIETER. M. S. Política criminal atuarial: a criminologia do fim da história. Rio de Janeiro: Revan, 2013.

FRACASSO, L. Comunidades Terapêuticas: histórico e regulamentações. In: Aberta: Portal de formação a distância - sujeitos, contextos e drogas. Brasília, DF; 2017.

GARLAND, D. A cultura do controle: crime e ordem social na sociedade contemporânea; trad. apres. e notas. André Nascimento. Rio de Janeiro: Revan, 2014.

INSTITUTO DE PESQUISA ECONÔMICA APLICADA (IPEA). Perfil das comunidades terapêuticas brasileiras, Nota Técnica, n. 21. Brasília: IPEA, DIEST, 2017.

MACHADO, A. R. Uso prejudicial e dependência de álcool e outras drogas na agenda da saúde pública: um estudo sobre o processo de constituição da política pública de saúde do Brasil para usuários de álcool e outras drogas. 2006. Dissertação (Mestrado em Saúde Pública) - Programa de Pós-Graduação em Saúde Pública, Universidade Federal de Minas Gerais, Belo Horizonte, 2006.

NASCIMENTO, A. Apresentação. In: GARLAND, D. A cultura do controle: crime e ordem social na sociedade contemporânea. Trad. apres. e notas. André Nascimento. Rio de Janeiro: Revan, 2014.

NATALINO, M. A. C. Isolamento, disciplina e destino social em comunidades terapêuticas. In: SANTOS, M. P. G. (Org.). Comunidades terapêuticas: temas para reflexão. Rio de Janeiro: IPEA, 2018. 
PITTA, A. M. F. Um balanço da reforma psiquiátrica brasileira: instituições, atores e políticas. Ciência \& Saúde Coletiva. Rio de Janeiro, v. 16, n. 12, p. 4579-4589, dez. 2011.

RAUTER, C. Criminologia e subjetividade no Brasil. Rio de Janeiro: Revan, 2003.

ZAFFARONI, E. R. et al. Direito penal brasileiro: primeiro volume - Teoria Geral do Direito Penal. 2. ed. Rio de Janeiro: Editora Revan, 2003. $2015 \mathrm{a}$. O inimigo no direito penal. 3a. ed., 3. reimp. Rio de Janeiro, Revan, . El derecho latinoamericano en la fase superior del colonialismo. Passagens - Revista Internacional de História Política e Cultura Jurídica. Rio de Janeiro, v. 7, n. 2, p. 182-243, maio / ago. 2015b. 
